\title{
Health examination utilization in the visually disabled population in Taiwan: a nationwide population-based study
}

Yueh-Han Hsu ${ }^{1,2,3}$, Wen-Chen Tsai ${ }^{1 \dagger}$ and Pei-Tseng Kung ${ }^{4 *+}$

\begin{abstract}
Background: People with visual disabilities have increased health needs but face worse inequity to preventive health examinations. To date, only a few nationwide studies have analyzed the utilization of preventive adult health examinations by the visually disabled population. The aim of this study was to investigate the utilization of health examinations by the visually disabled population, and analyze the factors associated with the utilization.

Methods: Visual disability was certified by ophthalmologists and authenticated by the Ministry of the Interior (MOI), Taiwan. We linked data from three different nationwide datasets (from the MOl, Bureau of Health Promotion, and National Health Research Institutes) between 2006 and 2008 as the data sources. Independent variables included demographic characteristics, income status, health status, and severity of disability; health examination utilization status was the dependent variable. The chi-square test was used to check statistical differences between variables, and a multivariate logistic regression model was used to examine the associated factors with health examination utilization.
\end{abstract}

Results: In total, 47,812 visually disabled subjects aged 40 years and over were included in this study, only $16.6 \%$ of whom received a health examination. Lower utilization was more likely in male subjects, in those aged 65 years and above, insured dependents and those with a top-ranked premium-based salary, catastrophic illness/injury, chronic diseases of the genitourinary system, and severe or very severe disabilities.

Conclusion: The overall health examination utilization in the visually disabled population was very low. Lower utilization occurred mainly in males, the elderly, and those with severe disabilities.

Keywords: Disability, Visual impairment, Health examination utilization, Health disparity

\section{Background}

People with disabilities have distinct healthcare needs, and they tend to experience chronic health problems earlier than the general population [1]. The prevalence of chronic disease is two to three times higher in people with disabilities [2], and the risk of co-morbidities such as cardiovascular disease and stroke is also increased $[1,3]$. However, previous research has demonstrated that the health service needs of people with disabilities are not currently being met [4-6]. The visually disabled population, as with individuals with other disabilities,

\footnotetext{
* Correspondence: ptkung@asia.edu.tw

${ }^{\dagger}$ Equal contributors

${ }^{4}$ Department of Healthcare Administration, Asia University, No. 500 Lioufeng Road, Wufeng, Taichung 41354, R.O.C. Taiwan

Full list of author information is available at the end of the article
}

have less access to appropriate healthcare services [1,7] and are less likely to receive screening examinations [8]. They face enormous barriers in accessing proper preventive healthcare, including informational barriers, lack of services, lack of transport, inadequate resources or financial considerations, lack of social awareness, and lack of education and training of healthcare providers [9-11]. In terms of equity, we hypothesized that the visually disabled are being doubly marginalized.

Visual impairment is one of the major causes of disability in the United States and in Taiwan [12,13]. It has been estimated that the prevalence of visual disabilities will increase markedly during the next several decades, with an estimated 70\% increase in blindness and low vision by 2020 [14]. Vision loss contributes significantly 
to falls, fractures and restrictions in mobility [15], and to increased hospital length of stay and post-discharge requirements for rehabilitative care [16]. Severe bilateral visual impairments are associated with an increased risk of all-cause mortality and cardiovascular disease-related mortality [17], and are regarded as an independent predictor of mortality $[17,18]$.

Preventive health examinations are an important health promotion strategy [19-22]. They can help to identify diseases at an early stage, postpone the development of subsequent adverse outcomes, and significantly save healthcare resources and lives [19]. Recent research from the United States suggests that greater use of clinical preventive services can save more than two million life-years annually [20]. In Japan, Hozawa et al. reported that mortality rates are at least $26 \%$ lower among those undergoing health check-ups than those who do not [21]. In Taiwan, Deng et al. reported that for hypertension patients who attended a health examination program, over NT\$34,570 in healthcare costs were saved, and life-spans were increased by 128 days [22].

Equity of access to health care is an important factor in priority setting of a health care system [23,24]. Inequity in access to preventive health services has been shown to be closely related to differences in age, family income, gender, race/ethnicity, urban/rural residence, severity of disability, and education level [25-29].

In Taiwan, the government inaugurated the National Health Insurance (NHI) program in March 1995 to provide compulsory universal health care coverage including medical care services and preventive health services. To date, the NHI enrolls over $99.9 \%$ of the Taiwanese population [30] and has contracts with over $92 \%$ of all medical providers [31]. Since the launch of the NHI, investigations have reported there to be significant improvements in terms of equity of access to health care, greater financial risk protection, and the geographical distributions of physicians [32-35].

The overall utilization rate of adult health examinations in Taiwan has been reported to be $33.3 \%$ to $40.72 \%$ [36,37], and $46.8 \%$ in the elderly [19]. For the whole disabled population, the utilization rate has been reported to be $15.8 \%$ [13]. Although the utilization rate in the disabled population is much lower, disabilities are usually not factored into most studies on equity. To reduce the barriers to preventive health services and encourage health checks for the visually disabled population, it is necessary to obtain evidence from large-scale investigations regarding the associated factors of utilization of the preventive health services. Accordingly, the aim of this study was to examine the factors related to the utilization of health examinations by the visually disabled population. Identifying the barriers that prevent visually disabled people from participating in health examinations may help the authorities to conceive feasible strategies for this marginalized population.

\section{Methods}

\section{Preventive health services in Taiwan}

To promote the health of all people in Taiwan, the government has provided free preventive health services since 1995. These services are provided free (only a registration fee is required) to: (1) those aged 40-64 years once every three years; (2) those aged 65 years and over once a year; and (3) those with poliomyelitis aged 35 and over once a year. A registration fee of up to US $\$ 3$ may be required for people with no disabilities, although this is waived for people with disabilities. The health examination includes a physical examination, health education guidance, blood tests, and urinalysis.

\section{Study population}

This study focused on adults aged over 40 years with visual disabilities. Visual disability, like all other formally issued disabilities in Taiwan, was authenticated via a strict administrative process. Patients with poor vision were examined and certified at ophthalmology clinics, and then approved by the Ministry of the Interior (MOI), Taiwan.

\section{Data sources}

Three different nationwide datasets were used including the Disability Registration from the MOI 2008 (with access to demographic characteristics and severity of disabilities), the Health Insurance Medical Claims from the National Health Research Institutes 2008 (with access to income status and health status), and the Health Prevention Services File from the Bureau of Health Promotion from 2006 to 2008 (with access to health examination utilization status). This study has been approved by the research ethics committee in China Medical University and Hospital (IRB No. CMU-REC101-012).

\section{Relevant variables}

The demographic characteristics including gender, age, education level, marital status, aboriginal status (yes vs. no), and level of urbanization of residential area (district or township) were recorded. The definition of level of urbanization was designed by Liu et al. [38] and has been broadly utilized in relevant research. Urbanization was classified into 8 levels for all residential townships in Taiwan, with level 1 being the most urbanized areas and level 8 being the least urbanized areas. The severity of disability was classified as mild, moderate, severe and very severe.

Income status included a low-income household status (yes vs. no) and levels of premium-based monthly salary 
(PBMS). The low-income household status was defined as a household per capita income of below the minimum cost of living for that residential area. The levels of PBMS were the monthly income levels reported to the Bureau of National Health Insurance as the basis for insurance premium collection and are often used as the index for personal income. Those who are members of a family but without employment are enrolled as insured dependents in the National Health Insurance program.

Health status included catastrophic illness/injury (yes vs. no) and the presence of relevant chronic illnesses (including cancer, endocrine and metabolic diseases, mental disorders, diseases of the nervous system, diseases of the circulatory system, diseases of the respiratory system, diseases of the digestive system, diseases of the genitourinary system, diseases of the musculoskeletal system and connective tissue, disorders of the eye and adnexa, infectious diseases, congenital anomalies, diseases of the skin and subcutaneous tissue, diseases of the blood and bloodforming organs, and diseases of the ear and mastoid process). Whether or not each subject had utilized a health examination was also recorded (yes vs. no).

\section{Statistical analysis}

The chi-square test was used for descriptive analysis of the variables, with a $p$ value of less than 0.05 being considered statistically significant. Multivariate logistic regression analysis was subsequently used to examine the influencing factors on the utilization of health examinations. The independent variables included demographic characteristics, income status, health status, and severity of disability, and the use of health examinations (yes vs. no) was the dependent variable.

All analyses were performed using SAS statistical software (version 9.1 for Windows; SAS Institute, Inc., Cary, NC, USA).

\section{Results}

In total, 47,812 (23,450 female, 49.05\%; 24,362 male, $50.95 \%)$ visually disabled people were enrolled. The overall health examination utilization rate was $16.16 \%$ (females $17.12 \%$ vs. males $15.25 \%, p<0.001$ ), while the benchmark data for the general population during the study period was $33.3 \%$ to $40.72 \%$ [36,37]. In terms of age, over $70 \%$ of the cohort was over 60 years of age (Table 1). With regards to urbanization level, less visually disabled people lived in Level 4 and Level 8 areas $(<10 \%)$. Those who lived in Level 1 areas had a relatively lower utilization rate. In terms of PBMS, most subjects were in the insured dependent group (38.68\%), followed by those with a PBMS of $16500-22800$ (29.96\%) and $<15840$ (20.26\%) New Taiwan dollars (NTD), respectively. These three subgroups constituted $88.9 \%$ of the whole population, showing that the majority of the cohort either had limited income or were unemployed. The insured dependent subgroup and the subgroup with the highest PBMS (PBMS NTD 48200-57800) reported lower utilization rates (around $13 \%)$ than the overall utilization rate (Table 1).

Around three percent $(3.07 \%)$ of the population were classified as belonging to low-income households, however the health examination utilization rate in this subgroup was higher than for those who were not classified as being in low income households (17.41\% versus $16.12 \%)$. With regards to aboriginal status, $1.36 \%$ of the population was classified as being aborigines, and this group had a higher utilization rate than non-aboriginal people. In terms of education level, $61.64 \%$ of the population had a level of primary school or below and they had a significantly lower utilization rate. In terms of marital status, most of the population was married $(60.16 \%)$, and this subgroup had a higher utilization rate than the other subgroups. Those who had any catastrophic illness/injury (8.87\%) had a significantly lower utilization rate (12.71\%). Similarly, those who suffered from cancer also had a significantly lower utilization rate (12.64\%). Those with chronic diseases had a higher utilization rate than those without chronic diseases (Table 1). In terms of disability severity, those with severe and very severe disabilities had significantly lower utilization rates.

\section{Factors associated with the utilization of preventive health services}

Multivariate logistic regression analysis revealed the likelihood of utilization to be significantly lower in males compared to females after controlling for other variables (Table 2). Compared with the 40-44 years subgroup, the utilization probability in the 65-69 and $\geq 70$ years subgroups were $39 \%$ and $52 \%$ lower, respectively $(\mathrm{OR}=0.61$ and 0.48 , both $p<0.001)$. In comparison to Level 1 urbanization areas, the probabilities of utilization by residents in all other levels were significantly higher. In comparison to the PBMS NTD $<15840$ subgroup, the probability of utilization in the insured dependent subgroup was significantly lower $(\mathrm{OR}=0.92,95 \% \mathrm{CI}$ : $0.85-0.99, p=0.035)$, and that of the top level subgroup (NTD 48200-57800) was even lower (OR $=0.63,95 \%$ CI: $0.48-0.81, p=0.001)$. Those with catastrophic illness/injury had a much lower utilization probability $(\mathrm{OR}=0.64,95 \% \mathrm{CI}: 0.56-0.74, p<0.001)$. In terms of chronic diseases, after controlling for other variables, only the subgroup with diseases of the genitourinary system had a significantly lower probability of utilization $(\mathrm{OR}=$ 0.83, 95\% CI: $0.75-0.92, p<0.001)$, whereas those with most other chronic diseases had either comparable or higher probabilities of utilization. In comparison to those with mild disabilities, the probability of utilization in those with moderate disabilities was $8 \%$ lower, and $21 \%$ lower in 
Table 1 Characteristics and Chi-square analysis of the health examination utilization in the visually disabled population

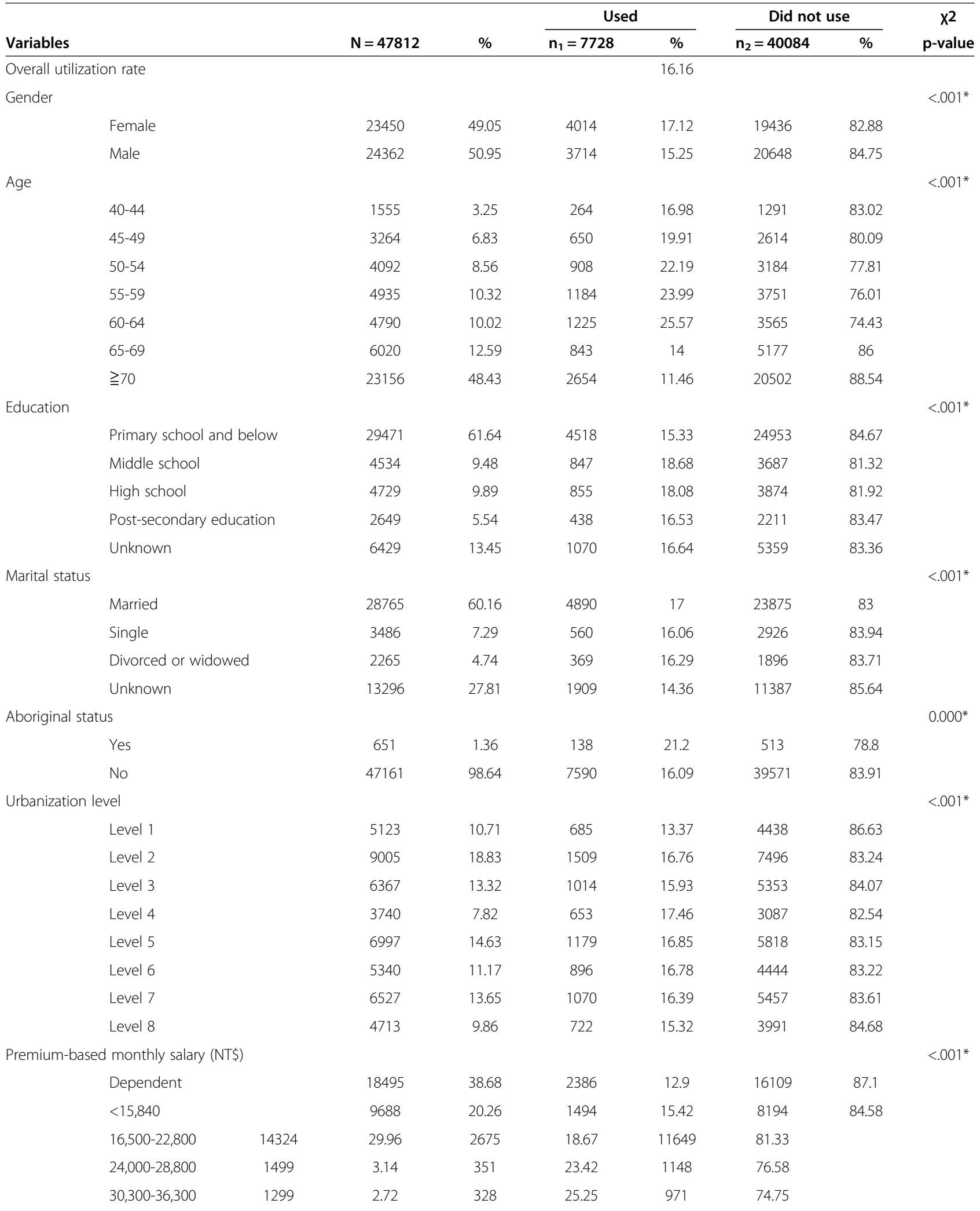


Table 1 Characteristics and Chi-square analysis of the health examination utilization in the visually disabled population (Continued)

$\begin{array}{ccccccc}38,200-45,800 & 1954 & 4.09 & 422 & 21.6 & 1532 & 78.4 \\ 48,200-57,800 & 553 & 1.16 & 72 & 13.02 & 481 & 86.98\end{array}$

Low-income household

Yes

Catastrophic illness/injury

Yes
No

Relevant chronic disease

Cancer

Yes
No

Endocrine and metabolic disorder

$\begin{array}{ll}\text { Yes } & 21852 \\ \text { No } & 25960\end{array}$

Mental disorder

Yes
No

Diseases of the nervous system

Yes

Diseases of the circulatory system

Yes

Diseases of the respiratory system

Yes
No

Diseases of the digestive system

$\begin{array}{ll}\text { Yes } & 1888 \\ \text { No } & 2892 \\ \text { tourinary system } & \end{array}$

Diseases of the genitourinary system

$\begin{array}{lcc}\text { Yes } & 3465 & 7.25 \\ \text { No } & 44347 & 92.75\end{array}$

Diseases of the musculoskeletal system and connective tissue

$\begin{array}{lll}\text { Yes } & 19214 & 40.19 \\ \text { No } & 28598 & 59.81\end{array}$

Diseases of the eyes and adnexa

$\begin{array}{lll}\text { Yes } & 21623 & 45.23 \\ \text { No } & 26189 & 54.77\end{array}$

Infectious disease

$\begin{array}{cccc}\text { Yes } & 2599 & 5.44 & 507 \\ \text { No } & 45213 & 94.56 & 7221\end{array}$

$\begin{array}{lcc}17.41 & 1214 & 82.59 \\ 16.12 & 38870 & 83.88\end{array}$

0.185

$<.001^{*}$

$\begin{array}{ccc}12.71 & 3701 & 87.29 \\ 16.5 & 36383 & 83.5\end{array}$


Table 1 Characteristics and Chi-square analysis of the health examination utilization in the visually disabled population (Continued)

\begin{tabular}{|c|c|c|c|c|c|c|c|c|}
\hline \multicolumn{8}{|c|}{ Congenital anomalies } & $<.001^{*}$ \\
\hline & Yes & 986 & 2.06 & 208 & 21.1 & 778 & 78.9 & \\
\hline & No & 46826 & 97.94 & 7520 & 16.06 & 39306 & 83.94 & \\
\hline & \multicolumn{7}{|c|}{ Diseases of skin and subcutaneous tissue } & $<.001^{*}$ \\
\hline & Yes & 5602 & 11.72 & 1090 & 19.46 & 4512 & 80.54 & \\
\hline & No & 42210 & 88.28 & 6638 & 15.73 & 35572 & 84.27 & \\
\hline & \multicolumn{7}{|c|}{ Diseases of blood and blood-forming organs } & $<.001^{*}$ \\
\hline & Yes & 2632 & 5.5 & 511 & 19.41 & 2121 & 80.59 & \\
\hline & No & 45180 & 94.5 & 7217 & 15.97 & 37963 & 84.03 & \\
\hline & \multicolumn{7}{|c|}{ Diseases of the ear and mastoid process } & $<.001^{*}$ \\
\hline & Yes & 5135 & 10.74 & 1060 & 20.64 & 4075 & 79.36 & \\
\hline & No & 42677 & 89.26 & 6668 & 15.62 & 36009 & 84.38 & \\
\hline \multicolumn{8}{|l|}{ Severity of disability } & $<.001^{*}$ \\
\hline Mild & & 15622 & 32.67 & 2993 & 19.16 & 12629 & 80.84 & \\
\hline Moderate & & 14050 & 29.39 & 2421 & 17.23 & 11629 & 82.77 & \\
\hline Severe & & 18138 & 37.94 & 2314 & 12.76 & 15824 & 87.24 & \\
\hline Very severe & 2 & 0 & 0 & 0 & 2 & 100 & & \\
\hline
\end{tabular}

${ }^{*} p<0.05$.

those with severe and very severe disabilities $(\mathrm{OR}=0.79$, 95\% CI: 0.74-0.84, $p<0.001)$.

Further, those with a low-income household status, aboriginal status, and lower education level, which are traditionally regarded as being disadvantaged subgroups, were found to have no significant differences in the probabilities of utilizing health examinations.

\section{Discussion}

This is the first comprehensive nationwide study to report the preventive health examination usage status in the visually disabled population in Taiwan. The findings show that the rate of using preventive health examinations in this cohort is extremely low $(16.16 \%)$ compared to the general population who were not visually impaired $(33.3 \%$ to $40.72 \%)$ [36,37]. In terms of age, over $60 \%$ of the cohort were aged 65 years or over. Chang et al. reported that the preventive health service utilization rate in the elderly in Taiwan is $46.8 \%$ [19], and another study reported that in aging Chinese Canadians, the rate is $76 \%$ [39]. These data suggest that most visually disabled people are elderly, and that the rate of using preventive health examinations in this population is very low. As indicated previously by evidence from different countries, an increased usage of preventive health examinations may improve health, reduce mortality and lower health care costs [20-22]. Therefore, it is imperative to enhance the utilization of preventive health examinations and improve the health status of this population.
Male gender, regardless of age, was significantly associated with a lower health examination usage, which is similar to previous reports $[13,21,26]$. In Taiwan, men still play the traditional role of familial financial support even if they have visual disabilities [40]. This could be ameliorated by advocating on-site health checks in companies through proper planning. In addition, men tend to pay less attention to their own healthcare in Taiwan [41]. Further health education and encouraging couples to attend examinations may be helpful in this regard.

Of those who were found to have lower preventive health examination utilization, certain subgroups could be considered to be disadvantaged with regards to healthcare resources, possibly due to lower access. They included the insured dependent subgroup, the elderly population, and those with a moderate or worse severity of disability. These subgroups share certain common characteristics. First, they are typical disadvantaged groups who are unemployed, with illnesses or senility, and need financial or transportation assistance. Second, they lack the personal ability to seek health services. Third, they may be reluctant to become a burden on their family. Several recommendations to enhance health examination utilization in these marginalized subgroups have been reported. For the disabled, transportation is an important barrier to access to health services in addition to financial constraints and communication difficulties $[42,43]$. Free transportation is widely available in Taiwan [44], however it is used less frequently by people with disabilities. In addition, patient- 
Table 2 Logistic regression analysis of the health examination utilization probability in the visually disabled population

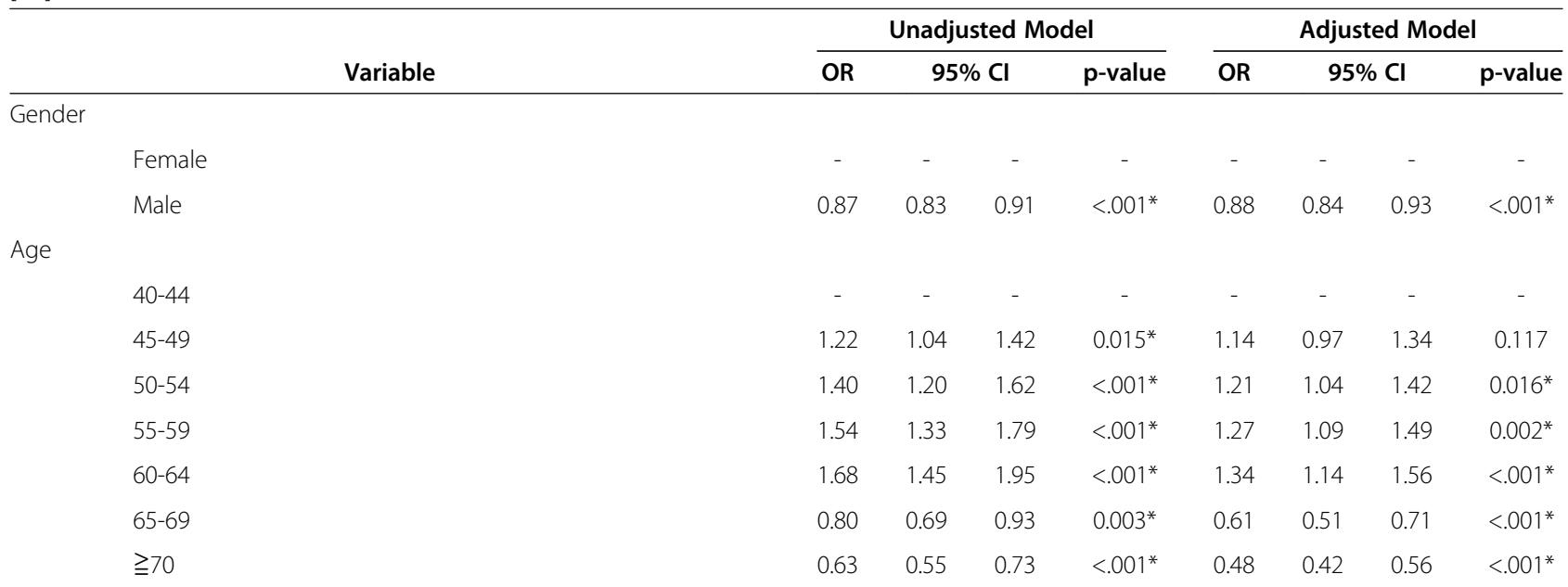

Education

$$
\begin{aligned}
& \text { Primary school and below } \\
& \text { Middle school } \\
& \text { High school } \\
& \text { Post-secondary education } \\
& \text { Unknown }
\end{aligned}
$$

Marital status

Married
Single
Divorced or widowed
Unknown

Aboriginal status

No

Urbanization level

$$
\begin{aligned}
& \text { Level } 1 \\
& \text { Level } 2 \\
& \text { Level } 3 \\
& \text { Level } 4 \\
& \text { Level } 5 \\
& \text { Level } 6 \\
& \text { Level } 7 \\
& \text { Level } 8
\end{aligned}
$$

Premium based monthly salary (NT\$)

$$
\begin{aligned}
& <15,840 \\
& \text { Dependent } \\
& 16,500-22,800 \\
& 24,000-28,800 \\
& 30,300-36,300 \\
& 38,200-45,800 \\
& 48,200-57,800
\end{aligned}
$$

$\begin{array}{cccccccc}1.27 & 1.17 & 1.38 & <.001^{*} & 1.04 & 0.95 & 1.13 & 0.447 \\ 1.22 & 1.13 & 1.32 & <.001^{*} & 1.02 & 0.93 & 1.11 & 0.713 \\ 1.09 & 0.98 & 1.22 & 0.1 & 1.06 & 0.94 & 1.19 & 0.372 \\ 1.10 & 1.03 & 1.19 & 0.009^{*} & 1.07 & 0.99 & 1.16 & 0.074\end{array}$

$\begin{array}{llllllll}1.07 & 0.97 & 1.18 & 0.164 & 1.00 & 0.91 & 1.11 & 0.958 \\ 1.02 & 0.88 & 1.17 & 0.819 & 0.98 & 0.84 & 1.14 & 0.767 \\ 0.88 & 0.79 & 0.97 & 0.011^{*} & 0.85 & 0.76 & 0.94 & 0.003^{*}\end{array}$

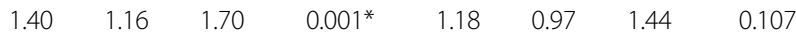

$\begin{array}{llllllll}1.30 & 1.18 & 1.44 & <.001^{*} & 1.30 & 1.17 & 1.44 & <.001^{*} \\ 1.23 & 1.11 & 1.36 & <.001^{*} & 1.27 & 1.14 & 1.42 & <.001^{*} \\ 1.37 & 1.22 & 1.54 & <.001^{*} & 1.38 & 1.22 & 1.56 & <.001^{*} \\ 1.31 & 1.19 & 1.45 & <.001^{*} & 1.41 & 1.26 & 1.57 & <.001^{*} \\ 1.31 & 1.17 & 1.46 & <.001^{*} & 1.40 & 1.25 & 1.58 & <.001^{*} \\ 1.27 & 1.15 & 1.41 & <.001^{*} & 1.46 & 1.30 & 1.63 & <.001^{*} \\ 1.17 & 1.05 & 1.31 & 0.006^{*} & 1.27 & 1.12 & 1.44 & <.001^{*}\end{array}$

$\begin{array}{cccccccc}0.81 & 0.76 & 0.87 & <.001^{*} & 0.92 & 0.85 & 0.99 & 0.035^{*} \\ 1.26 & 1.18 & 1.35 & <.001^{*} & 1.16 & 1.07 & 1.26 & <.001^{*} \\ 1.68 & 1.47 & 1.91 & <.001^{*} & 1.17 & 1.01 & 1.34 & 0.034^{*} \\ 1.85 & 1.62 & 2.12 & <.001^{*} & 1.21 & 1.04 & 1.39 & 0.013^{*} \\ 1.51 & 1.34 & 1.71 & <.001^{*} & 1.11 & 0.98 & 1.27 & 0.11 \\ 0.82 & 0.64 & 1.06 & 0.128 & 0.63 & 0.48 & 0.81 & 0.001^{*}\end{array}$


Table 2 Logistic regression analysis of the health examination utilization probability in the visually disabled population (Continued)

\begin{tabular}{|c|c|c|c|c|c|c|c|c|}
\hline \multicolumn{9}{|l|}{ Low-income household } \\
\hline No & - & - & - & - & - & - & - & - \\
\hline Yes & 1.10 & 0.96 & 1.26 & 0.186 & 1.03 & 0.89 & 1.21 & 0.677 \\
\hline \multicolumn{9}{|l|}{ Catastrophic illness/injury } \\
\hline No & - & - & - & - & - & - & - & - \\
\hline Yes & 0.74 & 0.67 & 0.81 & $<.001^{*}$ & 0.64 & 0.56 & 0.74 & $<.001^{*}$ \\
\hline \multicolumn{9}{|l|}{ Relevant chronic disease } \\
\hline Cancer & 0.74 & 0.65 & 0.84 & $<.001^{*}$ & 1.14 & 0.95 & 1.37 & 0.172 \\
\hline Endocrine and metabolic disorder & 1.64 & 1.56 & 1.72 & $<.001^{*}$ & 1.22 & 1.15 & 1.30 & $<.001^{*}$ \\
\hline Mental disorder & 1.44 & 1.37 & 1.52 & $<.001^{*}$ & 1.16 & 1.09 & 1.24 & $<.001^{*}$ \\
\hline Diseases of the nervous system & 1.31 & 1.23 & 1.40 & $<.001^{*}$ & 0.99 & 0.92 & 1.06 & 0.697 \\
\hline Diseases of the circulatory system & 1.42 & 1.35 & 1.49 & $<.001^{*}$ & 1.17 & 1.10 & 1.24 & $<.001^{*}$ \\
\hline Diseases of the respiratory system & 1.41 & 1.34 & 1.49 & $<.001^{*}$ & 1.21 & 1.14 & 1.29 & $<.001^{*}$ \\
\hline Diseases of the digestive system & 1.58 & 1.50 & 1.66 & $<.001^{*}$ & 1.24 & 1.17 & 1.31 & $<.001^{*}$ \\
\hline Diseases of the genitourinary system & 1.05 & 0.96 & 1.16 & 0.272 & 0.83 & 0.75 & 0.92 & $<.001^{*}$ \\
\hline Diseases of the musculoskeletal system and connective tissue & 1.64 & 1.56 & 1.73 & $<.001^{*}$ & 1.38 & 1.31 & 1.46 & $<.001^{*}$ \\
\hline Diseases of the eyes and adnexa & 1.43 & 1.36 & 1.50 & $<.001^{*}$ & 1.13 & 1.07 & 1.19 & $<.001^{*}$ \\
\hline Infectious disease & 1.28 & 1.15 & 1.41 & $<.001^{*}$ & 1.07 & 0.96 & 1.20 & 0.194 \\
\hline Congenital anomalies & 1.40 & 1.20 & 1.63 & $<.001^{*}$ & 1.10 & 0.94 & 1.29 & 0.255 \\
\hline Diseases of skin and subcutaneous tissue & 1.30 & 1.21 & 1.39 & $<.001^{*}$ & 1.08 & 1.00 & 1.17 & 0.053 \\
\hline Diseases of blood and blood-forming organs & 1.27 & 1.15 & 1.40 & $<.001^{*}$ & 1.05 & 0.95 & 1.17 & 0.335 \\
\hline Diseases of the ear and mastoid process & 1.41 & 1.31 & 1.51 & $<.001^{*}$ & 1.10 & 1.02 & 1.19 & $0.015^{*}$ \\
\hline \multicolumn{9}{|l|}{ Severity of disability } \\
\hline Mild & - & - & - & - & - & - & - & - \\
\hline Moderate & 0.88 & 0.83 & 0.93 & $<.001^{*}$ & 0.92 & 0.87 & 0.98 & $0.011^{*}$ \\
\hline Severe + Very severe & 0.62 & 0.58 & 0.66 & $<.001^{*}$ & 0.79 & 0.74 & 0.84 & $<.001^{*}$ \\
\hline
\end{tabular}

${ }^{*} \mathrm{p}<0.05$.

family support groups have been developed for patients with cancer or disabilities, and have been shown to be helpful in improving adjustment and self-reliance [45,46]. To boost the utilization rate in this subgroup, healthcare authorities may need to address these points by providing more resources and initiative services.

People dwelling in the least urbanized regions such as the offshore islands and remote areas, aborigines, those with a low income, and those with lower education levels are traditionally considered to be disadvantaged groups and are expected to experience worse healthcare equity. However, the utilization rates in these groups were not lower in this study. Mobile health services and special programs initiated by the government to provide healthcare services to the remote and mountainous areas provide good healthcare access and may be the reason for the comparable utilization rates. In addition, the costs for the low-income households are covered by the Taiwan welfare system for co-payments per visit and
National Health Insurance monthly premiums, and this may have played a role in enhancing preventive health service utilization in this disadvantaged group. Finally, those with a lower education level unexpectedly had a comparable utilization, which implies that, in Taiwan, other demographic factors such as age, income, or health status may be more closely associated with inequity.

Other subgroups that were found to have lower utilization rates were not considered to be disadvantaged groups, and may have had more health service alternatives. This includes the subgroup dwelling in the most urbanized region (Level 1), and the subgroup reporting the highest income (the subgroup with the top-ranked PBMS). These results seem to be in contrast to other published reports; however they represent the subjects with a higher socio-economic status who may have more options for better self-paid preventive health services. In addition, these subjects might belong to health clubs which provide top-level health check programs, and 
therefore forego the free lower level preventive health checks provided by the National Health Insurance program.

Those with catastrophic illnesses and those with chronic systemic diseases of the genitourinary system were the two subgroups that had the lowest usage. However, these subjects would already have their preventive health service needs satisfied by scheduled regular check-ups at specialist clinics due to the underlying illness. All co-payments for such health services are exempt due to the status of having a catastrophic illness, and thus these patients would most likely not require the free standard preventive health checks provided by the National Health Insurance program.

There are some limitations to this study. First, utilization of healthcare services is closely related to understanding the health service and social welfare systems, and this can be challenging for those who are unfamiliar with these systems. Second, this is a secondary dataset research based on three different data files. Factors such as health beliefs and family history of illnesses may influence the utilization of health examinations, however these factors were not included in the datasets. In addition, PBMS but not true income data was used for analysis, which may not represent the true income levels. Third, only those aged 40 or above were included in this study and extrapolation of the results to younger age groups would be inappropriate.

\section{Conclusion}

The overall preventive health examination utilization rate in the visually disabled population is very low in Taiwan. The subgroups with lower utilization included male gender, elderly subjects aged 65 years and above, subjects living in the most urbanized regions, dependent subjects, subjects with a higher income level, subjects with catastrophic illnesses and genitourinary system diseases, and subjects with moderate or more severe disabilities. These findings have important implications for the healthcare policy makers who seek to reduce health disparity and enhance equity of healthcare for the visually disabled population. More resources should be allocated to address the issue of inequity in accessing healthcare in Taiwan.

\section{Abbreviations}

MOI: The Ministry of the Interior; PBMS: Premium-based monthly salary.

\section{Competing interests}

The authors declare that they have no competing interests.

\section{Authors' contributions}

WCT and PTK contributed to the conception and design of the study and to statistical analysis. YHH and WCT wrote the first draft of the manuscript. All authors participated in the interpretation of data for important intellectual content, and revised and approved the final version of the manuscript.

\section{Acknowledgements}

This study was supported by a grant (CMU99-ASIA-19) from China Medical University and Asia University. The health examination files were obtained from the Bureau of Health Promotion, Taiwan. We are also grateful for use of the National Health Insurance Research Database provided by the Department of Health, Taiwan, R.O.C. The interpretations and conclusions contained herein do not represent those of the Bureau of Health Promotion in Taiwan.

\section{Author details}

'Department of Health Services Administration, China Medical University, Taichung 40402, R.O.C. Taiwan. ${ }^{2}$ Department of Internal Medicine, Ditmanson Medical Foundation Chia-Yi Christian Hospital, Chia-Yi 60002, R.O.C. Taiwan.

${ }^{3}$ Department of Nursing, Min-Hwei Junior College of Health Care Management, Tainan 73658, R.O.C. Taiwan. ${ }^{4}$ Department of Healthcare Administration, Asia University, No. 500 Lioufeng Road, Wufeng, Taichung 41354, R.O.C. Taiwan.

Received: 18 March 2013 Accepted: 29 November 2013 Published: 5 December 2013

\section{References}

1. Dejong G, Palsbo SE, Beatty PW, Jones GC, Knoll T, Neri MT: The organization and financing of health services for persons with disabilities. Milbank Q 2002, 80(2):261-301.

2. Kinne S, Patrick DL, Doyle DL: Prevalence of secondary conditions among people with disabilities. Am J Public Health 2004, 94(3):443-445.

3. Havercamp SM, Scandlin D, Roth M: Health disparities among adults with developmental disabilities, adults with other disabilities, and adults not reporting disability in North Carolina. Public Health Rep 2004, 119(4):418-426.

4. Howells $\mathrm{G}$ : Are the medical needs of mentally handicapped adults being met? J R Coll Gen Pract 1986, 36(291):449-453.

5. Lennox NG, Kerr MP: Primary health care and people with an intellectual disability: the evidence base. J Intellect Disabil Res 1997, 41(Pt 5):365-372.

6. Wilson DN, Haire A: Health care screening for people with mental handicap living in the community. BMJ 1990, 301(6765):1379-1381.

7. Beatty PW, Hagglund KJ, Neri MT, Dhont KR, Clark MJ, Hilton SA: Access to health care services among people with chronic or disabling conditions: patterns and predictors. Arch Phys Med Rehabil 2003, 84(10):1417-1425.

8. Park JH, Lee JS, Lee JY, Gwack J, Park JH, Kim YI, Kim Y: Disparities between persons with and without disabilities in their participation rates in mass screening. Eur J Public Health 2009, 19(1):85-90.

9. Watson EK, Moles DR, Kumar N, Porter SR: The oral health status of adults with a visual impairment, their dental care and oral health information needs. Br Dent J 2010, 208(8):E15.

10. Lebowitz EJ: An introduction to dentistry for the blind. Dent Clin North Am 1974, 18(3):651-669.

11. Edwards DM, Merry AJ: Disability part 2: access to dental services for disabled people. A questionnaire survey of dental practices in Merseyside. Br Dent J 2002, 193(5):253-255.

12. Centers for Disease C, Prevention: Prevalence of disabilities and associated health conditions among adults-United States, 1999. MMWR Morb Mortal Wkly Rep 2001, 50(7):120-125.

13. Kung PT, Tsai WC, Li YH: Determining factors for utilization of preventive health services among adults with disabilities in Taiwan. Res Dev Disabil 2012, 33(1):205-213.

14. Eye Diseases Prevalence Research Group, Congdon N, O'Colmain B, Klaver CC, Klein R, Munoz B, Friedman DS, Kempen J, Taylor HR, Mitchell P: Causes and prevalence of visual impairment among adults in the United States. Arch Ophthalmol 2004, 122(4):477-485.

15. Cacciatore F, Abete P, Maggi S, Luchetti G, Calabrese C, Viati L, Leosco D, Ferrara N, Vitale DF, Rengo F: Disability and 6-year mortality in elderly population. Role of visual impairment. Aging Clin Exp Res 2004, 16(5):382-388.

16. Morse AR, Yatzkan E, Berberich B, Arons RR: Acute care hospital utilization by patients with visual impairment. Arch Ophthalmol 1999, 117(7):943-949.

17. Lee DJ, Gomez-Marin O, Lam BL, Zheng DD: Visual acuity impairment and mortality in US adults. Arch Ophthalmol 2002, 120(11):1544-1550. 
18. McCarty CA, Nanjan MB, Taylor HR: Vision impairment predicts 5 year mortality. Brit J Opthalmol 2001, 85(3):322-326.

19. Chang WC, Lan TH, Ho WC, Lan TY: Factors affecting the use of health examinations by the elderly in Taiwan. Arch Gerontol Geriatr 2010, 50(Suppl 1):S11-16.

20. Maciosek MV, Coffield AB, Flottemesch TJ, Edwards NM, Solberg LI: Greater use of preventive services in U.S. health care could save lives at little or no cost. Health Affair 2010, 29(9):1656-1660

21. Hozawa A, Kuriyama S, Watanabe I, Kakizaki M, Ohmori-Matsuda K, Sone T, Nagai M, Sugawara Y, Nitta A, Li Q, et al: Participation in health check-ups and mortality using propensity score matched cohort analyses. Prev Med 2010, 51(5):397-402.

22. Deng BH, Liu HW, Pan PC, Mau LW, Chiu HC: Cost-effectiveness of elderly health examination program: the example of hypertension screening. Kaohsiung J Med Sci 2007, 23(1):17-24.

23. Rudan I, Gibson J, Kapiriri L, Lansang MA, Hyder AA, Lawn J, Darmstadt GL, Cousens S, Bhutta ZA, Brown KH, et al: Setting priorities in global child health research investments: assessment of principles and practice. Croat Med J 2007, 48(5):595-604.

24. Kapiriri L, Norheim OF: Criteria for priority-setting in health care in Uganda: exploration of stakeholders' values. Bull World Health Organ 2004, 82(3):172-179

25. Smith RA, Cokkinides V, Eyre HJ: Cancer screening in the United States, 2007: a review of current guidelines, practices, and prospects. CA Cancer J Clin 2007, 57(2):90-104.

26. Owens GM: Gender differences in health care expenditures, resource utilization, and quality of care. J Manag Care Pharm 2008, 14(3 Suppl):2-6.

27. Chan L, Doctor JN, MacLehose RF, Lawson H, Rosenblatt RA, Baldwin LM, Jha A: Do Medicare patients with disabilities receive preventive services? A population-based study. Arch Phys Med Rehabil 1999, 80(6):642-646.

28. Makuc DM, Freid VM, Kleinman JC: National trends in the use of preventive health care by women. Am J Public Health 1989, 79(1):21-26.

29. Vaidya V, Partha G, Howe J: Utilization of preventive care services and their effect on cardiovascular outcomes in the United States. Risk Manag Healthc Policy 2011, 4:1-7. (doi):10.2147/RMHP.S15777. Epub 12011 Jan 15719

30. Bureau of National Health Insurance Department of Health, Executive Yuan: Universal Health Coverage in Taiwan. Taipei, Taiwan: Bureau of National Health Insurance, Department of Health, Executive Yuan; 2012. 2.

31. Bureau of National Health Insurance Department of Health, Executive Yuan: NHI 2012-2013 Annual Report. Taipei, Taiwan: Bureau of National Health Insurance, Department of Health, Executive Yuan; 2012. 76.

32. Lu JF, Hsiao WC: Does universal health insurance make health care unaffordable? Lessons from Taiwan. Health Aff (Millwood) 2003, 22(3):77-88.

33. Yang $\mathrm{CH}$, Huang YT, Hsueh YS: Redistributive effects of the National Health Insurance on physicians in Taiwan: a natural experiment time series study. Int J Equity Health 2013, 12:13. (doi):10.1186/1475-9276-1112-1113.

34. Lu JF, Leung GM, Kwon S, Tin KY, Van doorslaer E, O'Donnell O: Horizontal equity in health care utilization evidence from three high-income Asian economies. Soc Sci Med 2007, 64(1):199-212. Epub 2006 Oct 2002

35. Huang N, Yip W, Chou YJ, Wang PJ: The distribution of net benefits under the National Health Insurance programme in Taiwan. Health Policy Plan 2007, 22(1):49-59. Epub 2006 Dec 2019.

36. Ministry of Health and Welfare Taiwan: The statistics of preventive health services utilization. Taipei; 2012. Last access date: 2012 Aug 24. Available from URL:http://www.mohw.gov.tw/cht/DOS/Statistic.aspx? f_list_no=312\&fod_list_no=2643 (in Chinese).

37. Tsai $W-C$, Kung P-T: Disabled people's utilization of prevention examinations and associated factors. Taichung: China Medical University; 2010:1-241.

38. Liu CYHY, Chuang YL, Chen YJ, Weng WS, Liu JS, Liang KY: Incorporating Development Stratification of Taiwan Townships into Sampling Design of Large Scale Health Interview Survey. J Health Manag 2006, 4(1):1-22.

39. Lai DW, Kalyniak S: Use of annual physical examinations by aging Chinese Canadians. J Aging Health 2005, 17(5):573-591.

40. Wang C: Parenthood Beliefs and Work Values. Res Appl Psychol 2004, 22:201-216.

41. Chang LY, Yang ML, Jhao JY: Latent Healthcare Utilization Classification and Objective Health Measures. Tai J Soc 2011, 46:207-247.

42. Morrison EH, George V, Mosqueda L: British adults with chronic health conditions or impairments face significant barriers to accessing health services. Public Health 2012, 126(11):920-927. doi: 910.1016/j.puhe.2012. 1008.1003. Epub 2012 Sep 1015

43. Morrison EH, George V, Mosaueda L: Primary care for adults with physical disabilities: perceptions from consumer and provider focus groups. Fam Med 2008, 40(9):645-651.

44. Cheng TM: Taiwan's new national health insurance program: genesis and experience so far. Health Affair 2003, 22(3):61-76.

45. Lobato DJ, Kao BT: Integrated sibling-parent group intervention to improve sibling knowledge and adjustment to chronic illness and disability. J Pediatr Psychol 2002, 27(8):711-716.

46. Stewart R, Bhagwanjee A: Promoting group empowerment and self-reliance through participatory research: a case study of people with physical disability. Disabil Rehabil 1999, 21(7):338-345.

doi:10.1186/1472-6963-13-509

Cite this article as: Hsu et al:: Health examination utilization in the visually disabled population in Taiwan: a nationwide population-based study. BMC Health Services Research 2013 13:509.

\section{Submit your next manuscript to BioMed Central and take full advantage of:}

- Convenient online submission

- Thorough peer review

- No space constraints or color figure charges

- Immediate publication on acceptance

- Inclusion in PubMed, CAS, Scopus and Google Scholar

- Research which is freely available for redistribution

Submit your manuscript at www.biomedcentral.com/submit
C Biomed Central 